\title{
Interventions to Reduce Stereotyping Through Targeting Familiarity Preference
}

\author{
Emily Liu ${ }^{1}$ and Sori Baek* \\ ${ }^{1}$ Westwood High School, Westwood, MA, USA \\ \#Advisor
}

ABSTRACT

As people perceive familiar and unfamiliar individuals, they may subconsciously be influenced by stereotypical information that is harmful to the target. Stereotyping affects everyone and is connected to innate biases, noting familiarity preference in particular. Given the pervasiveness of this, we investigate the impact of familiarity preference on stereotypes through discussing and referencing research related to the topics of stereotypes, familiarity preference, and interventions to reduce stereotyping through targeting familiarity preference. Indeed, the warm feeling of recognition builds a trusting bond between individuals with the possibility to reduce stereotypical assumptions by affecting familiarity preference; therefore, we consider interventions by way of social media, education, and in-person exposure. Our discussion is essential in enhancing the understanding of how both stereotypes and familiarity preferences affect individuals' interactions and the necessity to reduce the damage that results from stereotyping.

\section{Introduction}

Stereotyping refers to the action of assuming an individual of a certain group possesses the characteristics of the whole group, and individual differences are ignored (Macrae \& Quadflieg, 2010). Consequently, this promotes biases which are difficult to erase or reconstruct, and they will significantly affect the judgements and behavior of our present and future generations (Macrae \& Quadflieg, 2010). The stereotypes can affect numerous aspects of the stereotyped group's existence, including psychical and mental health, academic and work performance, socialization, and more (see Wijk, Kolk, \& van Vliet, 1996 for example). It is pervasive and dangerously persistent and the issue of stereotypes will not naturally subside over time. Therefore, society must acknowledge and actively participate in reducing sources of prejudice.

To try to reduce stereotyping, one can consider targeting familiarity preference. Familiarity preference is the natural tendency for people to develop a preference to or more positive attitudes toward objects or individuals because they are familiar to them (Zajonc, 1968), and this familiarity preference is an innate characteristic that affects everyone (Rose et al., 1982; Thompson \& Trevathan, 2009; Mehler et al., 1978; Shinskey \& Munakata, 2005). Given that psychologists found that the mere exposure to a wide range of stimuli can result in familiarity preference (Moreland \& Beach, 1992), it is easy to see why familiarity preference may apply to interpersonal relationships as well. In this paper, I will use evidence about preferences for familiar people to support my argument that moderating people's familiarity preferences can help reduce stereotyping. In this report, we discuss stereotypes, familiarity preference, the impact of familiarity preference on stereotypes, and possible methods to reduce stereotyping through targeting familiarity preference. 


\section{Stereotypes}

Stereotypes are universal and affect all individuals, based on age, (Cuddy, Norton, \& Fisk, 2016; Chrisler, Barney, \& Palatino, 2016), sex (Heilman, 2012; Soklaridis et al., 2017; Sen \& Östlin, 2008; Travis, Howerton, \& Szymanski, 2012; Wijk, Kolk, \& van Vliet, 1996; Bailey et al., 2013; Lauzen, Lacombe-Duncan, 2016), and race (Zebrowitz, Matthew Bronstad, \& Lee, 2007; McGlothlin \& Killen, 2010; Hetey \& Eberhardt, 2018; Steele \& Aronson, 1995). Stereotypes affect people in many ways, including via "stereotype threat." A stereotype threat refers to being at risk of confirming a negative stereotypical characteristic of an individual's group as their own. People who are affected by stereotype threat are prone to underperform because of the extra pressure to succeed, threats to self-integrity and belonging, and/or priming the stereotype (Spencer, Logel, \& Davies, 2016). Stereotype threat impairs both academic learning and performance (Taylor \& Walton, 2011). Test-taking performance of African Americans can be negatively affected by stereotype threat as the African American participants were at risk of confirming the racial stereotype about their "substandard" intellectual ability (Steele \& Aronson, 1995). In terms of gender stereotypes, stereotype threat disrupts women's math performance because of their apprehension of confirming the stereotype about their "weaker" math skills than men (Spencer, Steele, \& Quinn, 1999).

Such stereotypes can affect many areas, including self-esteem, interactions and cross-race relationships, the equality in the criminal system, fairness in the workplace, and fairness in healthcare. We will discuss these forms of stereotyping in detail.

First, self-esteem can be undermined by stereotypes. For example, self-esteem of individuals with serious mental illness is harmed by internalizing stereotypes about mental illness (Corrigan, Rafacz, \& Rüsch, 2011). In general, when individuals apply stereotypes to themselves, they feel incapable of reaching personal goals and may give up, ultimately feeling defeated (Corrigan et al., 2015). Self-esteem is important because it promotes optimism and hope in reaching goals.

Second, stereotypes are harmful to social interactions that affect relationships. Stereotypes play an important role in social perception, behavior, and emotion (Rogers, Schröder, \& School, 2013). Social categorization and stereotypes produce intergroup expectations, or emotional prejudice, and behavior. Emotions and perceptions of warmth and competence greatly affect whether a stereotype translates to action, ultimately influencing how different social groups interact between each other (Cuddy et al. 2008). Similarly, students attending ethnically homogeneous schools exhibited higher levels of racial bias in their judgments of cross-race friendship than those from heterogeneous schools (McGlothlin \& Killen, 2010). It is concluded that racial stereotypes can harm cross-race peer interactions that are prevalent starting from a young age.

Third, stereotyping can harm equality in the criminal system. Unconscious racial stereotypes negatively affect criminal justice system decisions (Graham \& Lowery, 2004). In a survey in 2016, nearly half of Black respondents reported that due to their ethnicity, someone in the past year has acted as if they were suspicious of them (Pew Research Center, 2016). Indeed, a Black individual is five times more likely to be stopped by the police than a white individual, without just reason (NAACP). Unequal treatment based on race in the criminal justice system creates harmful racial disparities, particularly among African Americans, who are regularly and unfairly stereotyped as criminals (Hetey \& Eberhardt, 2018).

Fourth, in the workplace, stereotyping can lead to poor outcomes for people of marginalized groups. The quality of opportunities often varies unfairly based on gender. Gender stereotypes promote workplace bias against women (Heilman, 2012). Compared to their male counterparts, for example, women are often viewed as more submissive (Hilton \& Hippel, 1996). Due to such gender stereotypes, women may be negatively affected and limited from leadership positions (Soklaridis et al., 2017). Therefore, even if both males and female employees perform similarly, they may be judged by overgeneralized assumptions based on gender rather than evidence specific to the individual. This ultimately threatens women's chances to reach goals, succeed, and help to advance society. 
Fifth, ethnic stereotypes limit marginalized and minority groups from vital access to healthcare. Healthcare services are crucial for everyone in advancing and maintaining health. From 2013 to 2017, healthcare quality differed significantly between ethnic groups: white patients received better healthcare quality than $40 \%$ of Black patients, $40 \%$ of Native American patients, and 34\% of Hispanic patients in the US (AHRQ, 2018). Racial stereotypes lead to persistent discrimination and lack of adequate healthcare for African Americans (Cuevas, 2013) because they may be stereotyped and viewed negatively as hostile (Hilton \& Hippel, 1996) and unintelligent (Steele \& Aronson, 1995). Stereotypes hinder society's push toward achieving equity in healthcare, causing racial and gender inequity in the field (Sen \& Östlin, 2008).

Similarly, gender stereotypes limit women's access to healthcare and increase healthcare disparities (Travis, Howerton, \& Szymanski, 2012), negatively affecting women's overall quality of healthcare (Wijk, Kolk, \& van Vliet, 1996). These stereotypes cause harmful biases against women in the treatment of pain (Hoffmann \& Tarzia, 2001) because women who speak assertively, especially in a medical context, are stereotypically viewed as emotional and hysterical. Therefore, they receive worse quality pain-treatment than men behaving the same way. Transgender women lack adequate access to HIV-related healthcare due to pervasive transphobia and sexism in healthcare (Lacombe-Duncan, 2016). Ageism, sexism, and stereotypes harm older women in the healthcare system (Chrisler, Barney, \& Palatino, 2016).

Given these points, it's clear that stereotypes are pervasive and destructive, and we should strive to create a society that is less affected by stereotypes. Due to the tenacious nature of stereotyping, action must be taken to reduce and prevent the harm that they cause, particularly through familiarity preference.

\section{Possible relationship between familiarity preference and stereotyping}

We argue that affecting our familiarity preference is something we can do to reduce stereotypes and promote equality. Familiarity preference can be a powerful factor that can influence stereotyping because it is innate and universal (Rose et al., 1982; Shinskey \& Munakata, 2005; Thompson \& Trevathan, 2009; Mehler et al., 1978), and it affects our decision making in a wide range of subjects (Locke, 2011). In particular, it lays the foundation for the trust that builds relationships (Gefen, 2000). Importantly, familiarity was found to affect the development of certain stereotypes (Prothro \& Melikian, 1955). For example, it was found that familiarity promoted attraction and social desirability (Reis et al., 2011), which is strongly linked to biases that could be related to stereotyping. Furthermore, intergroup conflict and hostility is partly caused by familiarity preference and can produce negative stereotypes and biases (Stroebe, Lenkert, \& Jonas, 1988). Low familiarity of race faces promoted ingroup favoritism and negatively affected outgroup stereotyping (Zebrowitz, Matthew Bronstad, \& Lee, 2007), and increasing the familiarity reduced racial biases (McGlothlin \& Killen, 2010). These results suggest that interventions to moderate familiarity can be a powerful method to reduce stereotyping by increasing the positive emotions evoked by the sense of familiarity due to our innate familiarity bias.

\section{Methods}

\section{To reduce stereotypes via familiarity preference}

Given that familiarity preference may affect stereotypes, it may be possible to reduce stereotyping by affecting familiarity preference. We suggest three main routes of intervention that target familiarity preference to decrease stereotyping: in-person exposure, social media, and education. 


\section{In-person exposure}

First, in-person exposure to different social groups can have an impact on familiarity and attitudes toward groups, weakening usage of stereotypes through the natural increase of positive attitudes toward familiar stimuli (HarmonJones \& Allen, 2001). The benefits of diverse learning environments for students are extensively researched and clear. National stereotypes can be reduced through exposure to individuals of the outgroup (Stroebe, Lenkert, \& Jonas). Ethnically heterogeneous schools reduce racial biases through intergroup contact (McGlothlin \& Killen, 2010). Diverse learning environments may help to reduce the power of stereotypes against African Americans in college environments (Johnson-Ahorlu, 2013). In like manner, the familiarity stereotyping effect may be reduced with increased exposure to information that contrasts stereotypes (Garcia-Marques et al., 2016). Several studies support this, revealing that counter stereotypical media messages and news are effective in moderating stereotypes and reduce biases (Holt 2013; Liu et al., 2017; Ramasubramanian, 2007). Indeed, ongoing contact with people of different races, ethnicities, or sexual orientations effectively reduces general prejudice and prejudice toward different races, sexes, and sexual orientations (Berryman-Fink, 2006), especially with a focus on personal and individuated identities (Brewer \& Miller, 1984) with cooperative tasks to form meaningful relationships (Berryman-Fink, 2006). The exposure to diverse individuals would increase familiarity and through familiarity preference, create more positive trust in more relationships, and undermine negative stereotypes.

\section{Social media}

Second, media influences perceptions of the facts, norms, and values of society through the portrayal of social stereotypes (Tan, 1982). Since social media might have an impact on targeting stereotypes and familiarity bias, we assert that increased exposure to people in the outgroup through social media can decrease stereotyping; we suggest that people engage in social media for longer periods of time. In support of this idea, Bialski and Batorski found that online familiarity results in more trustworthy relationships offline (2009). In addition, exposure to diverse networking profiles was found to reduce social stereotypes through intergroup contact (Neubaum et al., 2020).

On the other hand, some researchers claimed that exposure to only radicalized groupthink and conformity on social media can increase stereotyping such that social media may reproduce stereotypes and marginalization (Dobson \& Knezevic, 2018). In fact, social media and television news increase stereotyping African Americans as criminals because they sometimes fit negative stereotypical information of the group (Intravia \& Pickett, 2019). Offensive content and online aggression on social media reinforces feminine stereotypes, resulting in harmful consequences for females (Felmlee, Inara Rodis, \& Zhang, 2020; Bailey et al., 2013).

Although there are harmful effects of social media on stereotyping, we note that we specifically refer to increasing the familiarity preference to reduce stereotyping; increased exposure to marginalized groups leads to familiarity, increases trust and positive attitudes toward targeted groups, and preferences for a wider range of groups may develop over negative attitudes and biased assumptions. To this end, we suggest modifying media content to increase diversity and social awareness to loosen social norms that may decrease stereotyping. Modifying gender role portrayals in the media to focus on marginalized groups may loosen traditional gender norms (Grau \& Zotos, 2016). The usage of media literacy art education may help to deconstruct lesbian and gay stereotypes in the media (Chung, 2007).

\section{Education}

Third, by educating people to be more aware of their own biases, people can be less influenced by familiarity bias that results in stereotyping. Instead of giving control to implicit biases toward familiar people, reinforcing awareness of 
them may help people to assess situations with more sympathy, positive attitudes, and reconsideration of categorizational assumptions. Training and teaching people, specifically law enforcement agencies in this study, about implicit biases seem to be effective in increasing desirability to create better relations and increase sympathy (Hetey \& Eberhardt, 2018). Instructing children about biases produced mostly positively effects in reducing ethnic prejudice and discrimination (Aboud, 2012). Diversity courses in higher education result in an increase in students' intergroup tolerance (Hogan \& Mallott, 2005). More specifically, Berryman-Fink found that diversity education in higher education reduces general prejudice and prejudice toward different races, sexes, and sexual orientations (2006). In line with our findings, such diversity courses may be effective in part due to exposure to more diverse individuals, resulting in increased familiarity, preference, and positive attitudes toward them. Additionally, instructing society, as consumers of the media, to be more critical of the media in an audience-centered approach may reduce racial stereotypes brought upon by news stories (Ramasubramanian, 2007).

\section{Discussion}

In this paper, we discussed the harmful effects of stereotypes and how we may be able to address those stereotypes by targeting our innate preference toward targets that are familiar. First, we defined stereotypes and familiarity preferences. Then, we addressed the possibility of reducing stereotyping and unfair social biases by targeting familiarity preference through social media, education, and in-person exposure.

The significance of stereotyping stems from its implicit quality, pervasiveness, persistence, and critical consequences. Principally, stereotypes are more destructive than not: we reflected on the accompanying dangers of the stereotype threat (which we defined as being at risk of confirming a negative stereotypical characteristic of an individual's group as their own), self-esteem, social interactions and relationships, inequality in the criminal justice system, unequal opportunities in work settings, and lack of adequate healthcare. We insisted that familiarity preference be an important topic to consider because people in all types of groups are affected by it to its innate characteristic. We argued that familiarity preference may be the cause of stereotyping, because familiarity lays the foundation for trust that builds relationships. Studies revealed that familiarity preference does in fact affect stereotypes.

Our central claim that familiarity preference can influence stereotyping is supported by Zebrowitz, Bronstad, and Lee, who asserted that familiar faces produced biases toward ingroup individuals (2007), such that own-race faces appeared more familiar, likable, competent, and safer. These findings support that increased exposure to the faces of different groups, will make them appear more familiar; subsequently, perceivers may associate positive feelings with a wider range of groups, thus reducing bias toward them and reducing their usage of negative stereotypes. Another support comes from the finding that familiarity triggers a positive feeling associated with a positive mood toward the targeted person (Garcia-Marques \& Mackie, 2000). Since the positive feeling of familiarity directly impacts people's judgments (Forgas, 1994; Mackie \& Worth, 1989; Schwarz, 1990), it may undermine negative attitudes derived from stereotypical thinking.

Despite our argument that we can try to combat stereotyping by moderating people's familiarity preference via interventions, some researchers claim that there is no link between familiarity preference and stereotyping. In a paper referring to Implicit Association Test (IAT) experiments, Dasgupta et al. claimed that preference for certain races is automatic and not due to familiarity (2000). Nevertheless, this paper is dissimilar to our argument because it disregards the participants' real world exposure to stereotypes and familiarity of different race faces preceding the experiment, weakening the reliability of "controlled" factors. We question the validity of the study's usage of photos as stimuli because of its hypothetical nature that lacked the interactive factors with real individuals. Reis et al. argue that in natural circumstances, social evaluation processes may differ in real encounters with individuals as opposed to hypothetical figures used in some experiments (2011). Familiarity triggers recognition that increases comfort, satisfaction, and perceived knowledge during interaction, favorably impacting attraction. This paper strengthens the link between familiarity and stereotyping because increased attraction and positive attitude may weaken an individual's 
reliance on negative categorizational information of a target, thereby reducing stereotyping. Kinoshita \& PeekO'Leary further validate our argument in asserting that the factor of familiarity is actually not ruled out when considering causes of preferences for certain races (2005).

Some other researchers even suggest that trying to affect familiarity may worsen stereotyping. Although at first glance this may seem contradictory, we argue that there are many differences between the methods used by these researchers and the papers we cited thus far in this report. First, a study by Smith et al. (2006) found that familiarity may increase stereotyping; however, this deviates from the studies mentioned in this paper because it referred to exposure without important factors of liking, individuated knowledge, and friendship that are often associated with familiarity bias in natural social interactions as described by Reis et al. Second, Hafner \& Stapel (2009), found that additional exposure increases stereotyping in certain cases in which the stereotyped person engages in stereotypical behavior. Their method is flawed because true control of participants' preexisting biases and variation of selected stereotypes used in the experiment is questionable. Furthermore, the study's method was parallel to that of Smith et al.; thus, we emphasize the flawed method of using hypothetical photos mentioned by both papers. As supported by Kinoshita and Peek-O'Leary, stereotypical thoughts may not truly be reflected in the study because the method did not require participants to process the photo stimuli deeply.

\section{Conclusion}

In conclusion, although there are varying interpretations of familiarity and its effects, we stand by the validity of our argument that familiarity preference can impact and limit stereotyping. We maintain that the warm feeling of recognition builds a trusting bond between individuals with the possibility to reduce harmful stereotypical assumptions beforehand.

Our paper is essential to the understanding of how familiarity preference affects stereotyping, and ways to reduce stereotyping through targeting our biases. To further our understanding and offer increased precision, developing studies to research the relationship between familiarity preference and stereotyping across different situations, particularly in live interaction, would be beneficial to advance the reduction of stereotyping. We believe that stereotyping individuals threatens the harmony of our society because it is one of the root causes of discrimination. Recent Anti-Asian hate crimes are indicative of such danger. As we co-exist in an increasingly digital world, it is easier for people to demonstrate hate and allow labels to become mass opinion. Thus, it is critical that we prevent the destructiveness of stereotyping through researching various means of minimizing it in-person and online, particularly by targeting familiarity preference.

\section{Acknowledgments}

I would like to thank Horizon Academic for the incredible opportunity to dive deeper into psychology and write my first review article. I would also like to give a special thanks to Ms. Sori Baek for her guidance, and my family for their unmatched support.

\section{References}

Smith, E. R., Miller, D. A., Maitner, A. T., Crump, S. A., Garcia-Marques, T., \& Mackie, D. M. (2006). Familiarity can increase stereotyping. Journal of Experimental Social Psychology, 42(4), 471-478.

Häfner, M., \& Stapel, D. A. (2009). Familiarity can increase (and decrease) stereotyping: heuristic processing or enhanced knowledge usability?. Social Cognition, 27(4), 615-622. Chicago 
Spencer, S. J., Logel, C., \& Davies, P. G. (2016). Stereotype threat. Annual Review of Psychology, 67, 415-437. https://doi.org/10.1146/annurev-psych-073115-103235

Steele, C. M., \& Aronson, J. (1995). Stereotype Threat and the Intellectual Test Performance of African Americans. Journal of Personality and Social Psychology, 69(5), 797-811. https://doi.org/10.1037/0022-3514.69.5.797

Spencer, S. J., Steele, C. M., \& Quinn, D. M. (1999). Stereotype Threat and Women's Math Performance. Journal of Experimental Social Psychology, 35(1), 4-28. https://doi.org/10.1006/jesp.1998.1373

Taylor, V. J., \& Walton, G. M. (2011). Stereotype threat undermines academic learning. Personality and Social Psychology Bulletin, 37(8), 1055-1067. https://doi.org/10.1177/0146167211406506

Cuddy, A. J. C., Norton, M. I., \& Fiske, S. T. (2016, September 1). Corrigendum to: This Old Stereotype: The Pervasiveness and Persistence of the Elderly Stereotype (10.1111/j.1540-4560.2005.00405.x). Journal of Social Issues. Blackwell Publishing Inc. https://doi.org/10.1111/josi.12185

Shinskey, L. J., Munakata, Y. (2005). Familiarity Breeds Searching: Infants Reverse Their Novelty Preferences When Reaching for Hidden Objects. Psychological Science, 16(8), 596-600.

Stroebe, W., Lenkert, A., \& Jonas, K. (1988). Familiarity May Breed Contempt: The Impact of Student Exchange on National Stereotypes and Attitudes. In The Social Psychology of Intergroup Conflict (pp. 167-187). Springer Berlin Heidelberg. https://doi.org/10.1007/978-3-642-52124-9 10

Prothro, E. T., \& Melikian, L. H. (1955). Studies in Stereotypes: V. Familiarity and the Kernel of Truth Hypothesis. Journal of Social Psychology, 41(1), 3-10. https://doi.org/10.1080/00224545.1955.9714248

Zebrowitz, L. A., Matthew Bronstad, P., \& Lee, H. K. (2007, April). The contribution of face familiarity to ingroup favoritism and stereotyping. Social Cognition. https://doi.org/10.1521/soco.2007.25.2.306

Garcia-Marques, T., Mackie, D. M., Maitner, A. T., \& Claypool, H. M. (2016). Moderation of the familiarity-stereotyping effect: The role of stereotype fit. Social Cognition, 34(2), 81-96. https://doi.org/10.1521/soco.2016.34.2.81

McGlothlin, H., \& Killen, M. (2010). Special issue article How social experience is related to children 's intergroup attitudes. European Journal of Social Psychology Eur., 40(June 2009), 625-634. https://doi.org/10.1002/ejsp

Gefen, D. (2000). E-commerce: The role of familiarity and trust. Omega, 28(6), 725-737. https://doi.org/10.1016/S0305-0483(00)00021-9

Reis, H. T., Maniaci, M. R., Caprariello, P. A., Eastwick, P. W., \& Finkel, E. J. (2011). In live interaction, does familiarity promote attraction or contempt? Reply to Norton, Frost, and Ariely (2011). Journal of Personality and Social Psychology, 101(3), 575-578. https://doi.org/10.1037/a0023471

Rindfleisch, A., \& Inman, J. J. (1998). Explaining the familiarity-liking relationship: Mere exposure, information availability, or social desirability? Marketing Letters, 9(1), 5-19. https://doi.org/10.1023/A:1007958302123 
Hetey, R. C., \& Eberhardt, J. L. (2018). The Numbers Don't Speak for Themselves: Racial Disparities and the Persistence of Inequality in the Criminal Justice System. Current Directions in Psychological Science, 27(3), 183-187. https://doi.org/10.1177/0963721418763931

Graham, S., Lowery, B.S. Priming Unconscious Racial Stereotypes About Adolescent Offenders. Law Hum Behav 28, 483-504 (2004). https://doi.org/10.1023/B:LAHU.0000046430.65485.1f

Heilman, M. E. (2012). Gender stereotypes and workplace bias. Research in Organizational Behavior, 32, 113-135. G. Sen \& P. Östlin (2008) Gender inequity in health: why it exists and how we can change it, Global Public Health, 3:sup1, 1-12, DOI: 10.1080/17441690801900795

Soklaridis, S., Kuper, A., Whitehead, C.R., Ferguson, G., Taylor, V.H. and Zahn, C. (2017), "Gender bias in hospital leadership: a qualitative study on the experiences of women CEOs", Journal of Health Organization and Management, Vol. 31 No. 2, pp. 253-268. https://doi.org/10.1108/JHOM-12-2016-0243

Rose, S. A., Gottfried, A. W., Melloy-Carminar, P., \& Bridger, W. H. (1982). Familiarity and novelty preferences in infant recognition memory: Implications for information processing. Developmental Psychology, 18(5), 704-713. https://doi.org/10.1037/0012-1649.18.5.704

Harmon-Jones, E., \& Allen, J. J. B. (2001). The role of affect in the mere exposure effect: Evidence from psychophysiological and individual differences approaches. Personality and Social Psychology Bulletin, 27(7), 889-898. https://doi.org/10.1177/0146167201277011

Dobson, K., \& Knezevic, I. (2018). “Ain't nobody got time for that!”: Framing and stereotyping in legacy and social media. Canadian Journal of Communication, 43(3), 381-397. https://doi.org/10.22230/cjc.2018v43n3a3378

Bialski, P., \& Batorski, D. (2009). From Online Familiarity to Offline Trust. In Social Computing and Virtual Communities (pp. 179-204). Chapman and Hall/CRC. https://doi.org/10.1201/9781420090437-c8

Intravia, J., \& Pickett, J. T. (2019). Stereotyping Online? Internet News, Social Media, and the Racial Typification of Crime. Sociological Forum, 34(3), 616-642. https://doi.org/10.1111/socf.12515

Aboud, Frances \& Tredoux, Colin \& Tropp, Linda \& Brown, Christia \& Niens, Ulrike \& Noor, Noraini. (2012). Interventions to reduce prejudice and enhance inclusion and respect for ethnic differences in early childhood: A systematic review. Developmental Review. 32. 307-336. 10.1016/j.dr.2012.05.001.

Grau, S. L., \& Zotos, Y. C. (2016). Gender stereotypes in advertising: A review of current research. International Journal of Advertising: The Review of Marketing Communications, 35(5), 761-770.

https://doi.org/10.1080/02650487.2016.1203556

Hogan, D.E., \& Mallott, M. (2005). Changing Racial Prejudice Through Diversity Education. Journal of College Student Development 46(2), 115-125. doi:10.1353/csd.2005.0015.

Hilton, J. L., \& Hippel, W. V. (1996). Stereotypes. Annual Review of Psychology, 47(1), 237-271. doi:10.1146/annurev.psych.47.1.237 
Travis, C. B., Howerton, D. M., \& Szymanski, D. M. (2012). Risk, Uncertainty, and Gender Stereotypes in Healthcare Decisions. Women \& Therapy, 35(3-4), 207-220. doi:10.1080/02703149.2012.684589

Wijk, C. M., Vliet, K. P., \& Kolk, A. M. (1996). Gender perspectives and quality of care: Towards appropriate and adequate health care for women. Social Science \& Medicine, 43(5), 707-720. doi:10.1016/0277-9536(96)00115-3

Neubaum, G., Sobieraj, S., Raasch, J., \& Riese, J. (2020). Digital destigmatization: How exposure to networking profiles can reduce social stereotypes. Computers in Human Behavior, 112, 106461. doi:10.1016/j.chb.2020.106461

Cuevas, Adolfo Gabriel, "Exploring Four Barriers Experienced by African Americans in Healthcare: Perceived Discrimination, Medical Mistrust, Race Discordance, and Poor Communication" (2013). Dissertations and Theses. Paper 615 .

Berryman-Fink, C. (2006). Reducing prejudice on campus: the role of intergroup contact in diversity education. College Student Journal, 40(3), 511+. Retrieved from https://link.gale.com/apps/doc/A150965816/AONE?u=mlin_b_massblc\&sid=AONE\&xid=e68de5ea

Hoffmann, D. E., \& Tarzian, A. J. (2001). The girl who cried pain: A bias against women in the treatment of pain. Journal of Law, Medicine and Ethics, 29(1), 13-27. https://doi.org/10.1111/j.1748-720x.2001.tb00037.x

Lacombe-Duncan, A. (2016, January 1). An Intersectional Perspective on Access to HIV-Related Healthcare for Transgender Women. Transgender Health. Mary Ann Liebert Inc. https://doi.org/10.1089/trgh.2016.0018

Chrisler, J. C., Barney, A., \& Palatino, B. (2016). Ageism can be Hazardous to Women's Health: Ageism, Sexism, and Stereotypes of Older Women in the Healthcare System. Journal of Social Issues, 72(1), 86-104. https://doi.org/10.1111/josi.12157

Robin Nicole Johnson-Ahorlu. (2013). "Our biggest challenge is stereotypes": Understanding Stereotype Threat and the Academic Experiences of African American Undergraduates. The Journal of Negro Education, 82(4), 382-392. doi:10.7709/jnegroeducation.82.4.0382

ZAJONC, R. B. (1968). ATTITUDINAL EFFECTS OF MERE EXPOSURE. Journal of Personality and Social Psychology, 9(2 PART 2), 1-27. https://doi.org/10.1037/h0025848

Corrigan, P. W., Rafacz, J., \& Rüsch, N. (2011). Examining a progressive model of self-stigma and its impact on people with serious mental illness. Psychiatry Research, 189(3), 339-343. https://doi.org/10.1016/j.psychres.2011.05.024

Tan, A. S. (1982). Television Use and Social Stereotypes. Journalism \& Mass Communication Quarterly, 59(1), 119-122. https://doi.org/10.1177/107769908205900120

Bailey, J., Steeves, V., Burkell, J., \& Regan, P. (2013). Negotiating with gender stereotypes on social networking sites: From "bicycle face” to Facebook. Journal of Communication Inquiry, 37(2), 91-112.

https://doi.org/10.1177/0196859912473777 
Felmlee, D., Inara Rodis, P. \& Zhang, A. Sexist Slurs: Reinforcing Feminine Stereotypes Online. Sex Roles 83, 1628 (2020). https://doi.org/10.1007/s11199-019-01095-Z

Thompson, L. A., \& Trevathan, W. R. (2009). Cortisol reactivity, maternal sensitivity, and infant preference for mother's familiar face and rhyme in 6-month-old infants. Journal of Reproductive and Infant Psychology, 27(2), 143-167. https://doi.org/10.1080/02646830801918463

Locke, P. (2011). Derivative Markets. In Behavioral Finance: Investors, Corporations, and Markets (pp. 613-627). John Wiley and Sons. https://doi.org/10.1002/9781118258415.ch33

Macrae, C. N., \& Quadflieg, S. (2010). Perceiving People. In Handbook of Social Psychology. John Wiley \& Sons, Inc. https://doi.org/10.1002/9780470561119.socpsy001012

Moreland, R. L., \& Beach, S. R. (1992). Exposure effects in the classroom: The development of affinity among students. Journal of Experimental Social Psychology, 28(3), 255-276. https://doi.org/10.1016/0022-1031(92)90055-O

Kinoshita, S., Peek-O'Leary, M. Does the compatibility effect in the race Implicit Association Test reflect familiarity or affect?. Psychonomic Bulletin \& Review 12, 442-452 (2005). https://doi.org/10.3758/BF03193786

Dasgupta, N., McGhee, D. E., Greenwald, A. G., \& Banaji, M. R. (2000). Automatic preference for White Americans: Eliminating the familiarity explanation. Journal of Experimental Social Psychology, 36(3), 316-328. https://doi.org/10.1006/jesp.1999.1418

Rogers, K. B., Schröder, T., \& Scholl, W. (2013). The Affective Structure of Stereotype Content. Social Psychology Quarterly, 76(2), 125-150. doi:10.1177/0190272513480191

Macrae, C. N., \& Bodenhausen, G. V. (2000). Social Cognition: Thinking Categorically about Others. Annual Review of Psychology, 51(1), 93-120. doi:10.1146/annurev.psych.51.1.93

Mehler, J., Bertoncini, J., Barriere, M., \& Jassik-Gerschenfeld, D. (1978). Infant Recognition of Mother's Voice. Perception, 7(5), 491-497. doi:10.1068/p070491

Corrigan, P. W., Bink, A. B., Schmidt, A., Jones, N., \& Rüsch, N. (2015). What is the impact of self-stigma? Loss of self-respect and the "why try" effect. Journal of Mental Health, 25(1), 10-15. doi:10.3109/09638237.2015.1021902

Cuddy, A. J. C., Fiske, S. T., \& Glick, P. (2008). Warmth and Competence as Universal Dimensions of Social Perception: The Stereotype Content Model and the BIAS Map. Advances in Experimental Social Psychology. https://doi.org/10.1016/S0065-2601(07)00002-0

Chung, S. K. (2007). Media Literacy Art Education: Deconstructing Lesbian and Gay Stereotypes in the Media. International Journal of Art \& Design Education, 26(1), 98-107. doi:10.1111/j.1476-8070.2007.00514.x

Ramasubramanian, S. (2007). Media-based Strategies to Reduce Racial Stereotypes Activated by News Stories. Journalism \& Mass Communication Quarterly, 84(2), 249-264. doi:10.1177/107769900708400204 
Holt, L. F. (2013). Writing the wrong: Can counter-stereotypes offset negative media messages about African Americans? Journalism and Mass Communication Quarterly, 90(1), 108-125. https://doi.org/10.1177/1077699012468699

Liu, F., Ford, D., Parnin, C., \& Dabbish, L. (2017). Selfies as social movements: Influences on participation and perceived impact on stereotypes. Proceedings of the ACM on Human-Computer Interaction, 1(CSCW).

https://doi.org/10.1145/3134707

Brewer, M. B., \& Miller, N. (1984). Beyond the Contact Hypothesis: Theoretical Perspectives on Desegregation. Groups in Contact, 281-302. doi:10.1016/b978-0-12-497780-8.50019-x

Wolf, Susan M., Feminism \& Bioethics: Beyond Reproduction (1996). Susan M. Wolf, FEMINISM AND BIOETHICS: BEYOND REPRODUCTION, New York: Oxford University Press, 1996, Available at SSRN:

https://ssrn.com/abstract $=1735656$

Lin, M. H., Kwan, V. S., Cheung, A., \& Fiske, S. T. (2005). Stereotype Content Model Explains Prejudice for an Envied Outgroup: Scale of Anti-Asian American Stereotypes. Personality and Social Psychology Bulletin, 31(1), 34-47. doi:10.1177/0146167204271320

Garcia-Marques, T., \& Mackie, D. M. (2000). The positive feeling of familiarity: Mood as an information processing regulation mechanism. In H. Bless \& J. P. Forgas (Eds.), The message within: The role of subjective experience in social cognition and behavior (p. 240-261).

Forgas, J. P. (1994). Sad and guilty? Affective influences on the explanation of conflict in close relationships. Journal of Personality and Social Psychology, 66(1) 56-68.

Mackie, D. \& Worth, L. T. (1989). Processing deficits and the mediation of positive affect in persuasion. Journal of Personality and Social Psychology, 57, 27-40.

Schwarz, N. (1990). Feelings as information: Informational and motivational functions of affective states. In E. T. Higgins \& S. Sorrentino (Eds.), Handbook of motivation and cognition, (pp 527-559). New York: Guilford.

2018 National Healthcare Quality and Disparities Report. (2018). Retrieved August 27, 2020, from https://www.ahrq.gov/sites/default/files/wysiwyg/research/findings/nhqrdr/2018qdr-final.pdf

Pew Research Center. (2016). On views of race and inequality, Blacks and Whites are worlds apart. Retrieved from http://www.pewsocialtrends.org/2016/06/27/on-views-of-race-and-inequality-blacks-and-whites-are-worlds-apart/

Criminal Justice Fact Sheet (2020). NAACP, an American organization. New York :National Association for the Advancement of Colored People, Retrieved from https://www.naacp.org/criminal-justice-fact-sheet/ 